\title{
Exploring the main factors driving a satisfactory use of the Moodle platform
}

\author{
Elena Ancuța Santi, Gabriel Gorghiu \\ Valahia University Targoviste \\ 13 Aleea Sinaia, 130004 Targoviste, \\ Romania \\ santi.ancalyahoo.ro, ggorghiulgmail.com
}

\author{
Costin Pribeanu \\ Academy of Romanian Scientists \\ 54 Splaiul Independentei, 050094 Bucharest, \\ Romania \\ costin.pribeanu@gmail.com
}

DOI: $10.37789 /$ rochi.2020.1.1.23

\begin{abstract}
E-learning platforms are largely used in educational institutions around the world, in hybrid, mixed or blended learning formats. The power of those platforms has been proved extensively in the period of the global pandemic being used as main frameworks for offering and achieving educational services. This work is an exploratory study aiming to analyze the contribution of the perceived ease of use, usefulness, and enjoyment to the satisfaction of using a Moodle e-learning platform. To do this, a structural modeling approach has been taken. The model testing results show that perceived enjoyment was the most important factor which suggests that, apart from being usable and useful, a learning platform should be also attractive and interesting.
\end{abstract}

\section{Keywords}

e-learning, Moodle, TAM, usability, perceived enjoyment, user satisfaction.

\section{ACM Classification}

D.2.2: Design tools and techniques. H5.2 User interfaces.

\section{INTRODUCTION}

Modern academic education is increasingly capitalizing on the features provided by Learning Management Systems (LMS) or Virtual Learning Environments (VLE), as relevant software applications able to manage online teaching and learning. At the moment, being generically defined as "platforms", such applications are largely used in educational institutions around the world, in hybrid, mixed or blended learning formats, mainly combining face-to-face education (performed in the classroom) with the instruction offered in the online environment.

The power of those platforms has been proved extensively in the period of the global pandemic, when LMSs and VLEs constituted the main frameworks for offering and achieving educational services, exclusively online. In almost all the cases, related platforms began to be exploited near their full potential, starting with offering presentations and teaching materials for students to evaluating their knowledge by using various test formats or producing various statistics. In this respect, the ordinary face-to-face communication between teacher and student has been transposed in an environment very familiar to the actual generation of youngers, with impact on ensuring the proper pedagogical and psychological support, but also on maintaining the spirit of competition or modeling the student's personality [11]. In any case, among the many features of such platforms, Epping [9] specifies that each of them provides an environment for teaching and learning without time or distance restrictions.

Currently, there is a multitude of e-learning platforms, with different characteristics of structure, functionality, accessibility, and attractiveness. One of the most commonly used LMS is Moodle - Modular Object-Oriented Dynamic Learning Environment, with more than 156000 sites in 241 countries, as the situation is stated in July 2020 [20].

The aim of this research is to explore the contribution of the perceived ease of use, usefulness, and enjoyment to the satisfaction of using an e-learning platform, during the pandemic time, more precisely, the second semester of the academic year 2019-2020 (March - June 2020).

In section 2, related work is discussed with a focus on the analyzed factors. The method and sample are presented in section 3. Specific results are discussed in section 4. The paper is ending with a conclusion in section 5 .

\section{RELATED WORK}

There are a series of studies in which the abovementioned factors were analyzed in different LMSs. In this respect, it can be started from Nielsen's remarks [15], who considered the product's usability as one of the main aspects that influence its acceptance by the specified users. To identify the best foldable model concerning the students' and teachers' educational needs, researchers in the e-learning area have studied various usability aspects of different platforms.

Aljawarneh [1] presented the main online learning platforms used in higher education, concluding that Moodle has proven to be the most effective in online learning, being preferred by many teachers and practitioners from all over the world. The actual statistics (July 2020), seem to be inline with this [20]: 27 million courses are uploaded in various Moodle environments and 216 million users benefit of them and its advantages, also emphasized by Oproiu [16].

Bremer \& Bryant [4] stated that $80 \%$ of students preferred Moodle vs Blackboard, being easier to use and having more tools that facilitate communication and collaboration. Pavlakou \& Kalachanis [17] presented the main Moodle strengths and its efficiency in adult learning (life-long learning). 
Even Dolendo [8], by comparing the usability of three LMSMoodle, Edmodo, and Schoology - stipulated that Edmodo was the most usable LMS, the recent study conducted by Szirmai [18] highlighted the students' preference for learning when using Moodle platform, as a "virtual extension of the teacher".

Anarinejad \& Mohammadi [2] and Usuf [19] revealed some strengths and weaknesses of the e-learning systems in higher education, but also Meiselwitz \& Sadera [13] show that a connection exists among the usability and students' learning outcomes in online learning environments.

The study of Calli et al. [5] analyzed the influence of four factors on the user's satisfaction in e-learning systems. In their model, the usage intention is determined by the user's satisfaction which, in turn, is influenced by three variables: perceived usefulness, perceived playfulness, and content effectiveness. Perceived usefulness has three antecedents: perceived playfulness, perceived ease of use, and content effectiveness. The results show that perceived usefulness has the main influence on satisfaction and the perceived playfulness has the main influence on the perceived usefulness.

Pereira et al. [7] also analyzed the influence of satisfaction on the continued use of a web learning system. In their model satisfaction has two main drivers which manifest in several factors: performance (perceived quality, perceived value, quality, usability, and value) and technology readiness (optimism and innovativeness).

\section{RESEARCH METHODOLOGY}

\section{Variables and hypotheses}

This research is grounded in the Technology Acceptance Model (TAM) and its further extensions that posit that the perceived ease of use, perceived usefulness, and perceived enjoyment are the main drivers of the technology acceptance and continued use [6]. As many authors pointed out, satisfaction is an important variable for the intention to continue using a system $[5,7]$. The following latent variables have been conceptualized and measured in this study: perceived ease of use (PEU), perceived enjoyment (PE), perceived usefulness of the platform (PU), and perceived satisfaction (SAT).

According to Davis et al. [6], the perceived ease of use refers to the belief that using a system is "free of effort". This means that the user will find it easy to understand, learn how to use, and operate a given system. The perceived usefulness is an extrinsic motivation that refers to the belief that using the system will "enhance job performance". The perceived enjoyment is an intrinsic motivation that refers to the belief that the system is "enjoyable in its own rights" [6].

The following hypotheses are tested in this study:

$H 1$. Perceived ease of use has a positive effect on perceived enjoyment $(\mathrm{PEU} \rightarrow \mathrm{PE})$.

H2. Perceived ease of use has a positive effect on the perceived usefulness (PEU $\rightarrow$ PU).

H3. Perceived ease of use has a positive effect on perceived satisfaction $(\mathrm{PEU} \rightarrow \mathrm{SAT})$.
H4. Perceived enjoyment has a positive effect on the perceived usefulness (PE $\rightarrow$ PU).

$H 5$. Perceived enjoyment has a positive effect on perceived satisfaction $(\mathrm{PE} \rightarrow \mathrm{SAT})$.

H6. Perceived usefulness has a positive effect on perceived satisfaction $(\mathrm{PU} \rightarrow \mathrm{SAT})$.

\section{Platform and sample}

In Valahia University, the courses on the Moodle platform are organized on different levels, for students registered at the license, master, doctorate, postgraduate or continuing education levels. At each mentioned level, the courses are structured by faculties. Within the faculties, the organization is done according to specializations.

Inside the platform, the student's area - after the authentication process - allows [11] to access the information uploaded for each course, to know the related tasks and deadlines, to view the course announcements, to know and manage the course calendar, to upload the own work in dedicated space or directory, to interact with the teacher by using synchronous and asynchronous channels (chat, forum), to know the results of the evaluation process.

To collect the measures, a questionnaire has been administrated to students in April 2020. After answering some general questions, the students have been asked to evaluate the items on a 5-points Likert scale.

A total of 155 students from Valahia University in Targoviste answered the questionnaire. After data screening for incomplete answers, 35 questionnaires have been eliminated so the working sample has 120 observations (76 females, 44 males). The age of participants is ranging from 20-29 years to 59-60 years. Most of them (85) have between 20 and 29 years old.

Preliminary testing of the model showed several low factor loadings so several items have been eliminated. The remaining observed variables are presented in Table 1 .

\section{Method}

Based on the analysis from the literature [3, 10, 12], the following goodness-of-fit (GOF) measures have been used: chi-square, normed chi-square $\left(\chi^{2} / d f\right)$, comparative fit index (CFI), standardized root mean square residual (SRMR), and root mean square error of approximation (RMSEA).

Data analysis was carried out using Lisrel 9.5 for Windows [14]. Model testing and validation were carried out following a two-step approach [3] including measurement and structural models.

\section{ANALYSIS AND RESULTS}

\section{Descriptive results}

The items, means, and standard deviations are presented in Table 1. All items have mean values greater than 3.50 showing a positive perception. Overall, the platform has been perceived as easy to use and useful, since the construct means are 4.03 , respectively 4.04 .

Data normality was investigated in terms of skewness and kurtosis. The values were all within the recommended level [12], supporting the moderate departure from normality for all variables. 
Table 1. Variables

\begin{tabular}{|c|c|c|}
\hline Item & Description & $\underline{\mathrm{SD}}$ \\
\hline PEU1 & $\begin{array}{l}\text { How to use the platform is clear and } \\
\text { intuitive }\end{array}$ & 3.910 .80 \\
\hline PEU2 & $\begin{array}{l}\text { The instructions on how to use this platform } \\
\text { are well organized }\end{array}$ & 4.040 .84 \\
\hline PEU3 & Finding information on this platform is easy & 3.970 .91 \\
\hline PEU4 & The terms used in the user interface are clear & 4.180 .80 \\
\hline PE1 & I like to use this platform & 3.810 .94 \\
\hline PE2 & Working with this platform is attractive & 3.711 .04 \\
\hline PE3 & $\begin{array}{l}\text { The educational activity on this platform is } \\
\text { interesting }\end{array}$ & 3.800 .99 \\
\hline PU1 & $\begin{array}{l}\text { The platform provides useful information on } \\
\text { the progress of my work }\end{array}$ & 4.010 .88 \\
\hline PU2 & $\begin{array}{l}\text { The platform is useful for the } \\
\text { communication student-teacher }\end{array}$ & 3.851 .01 \\
\hline PU3 & $\begin{array}{l}\text { The platform is useful for online educational } \\
\text { activities }\end{array}$ & 4.260 .87 \\
\hline SAT1 & $\begin{array}{l}\text { This platform satisfies my needs for online } \\
\text { education }\end{array}$ & 3.730 .98 \\
\hline SAT2 & $\begin{array}{l}\text { I am satisfied with the results I got working } \\
\text { on this platform. }\end{array}$ & 3.880 .92 \\
\hline SAT3 & I am satisfied with educational activity on & 3.690 .9 \\
\hline
\end{tabular}

\section{Measurement model}

Convergent and discriminant validity of the model has been analyzed using the procedure of Fornell and Larcker [10].

All standardized factor loadings are statistically significant. The item reliability $\left(R^{2}\right)$ values are ranging between 0.60 and 0.92, above the suggested standard of 0.50 [12]. Cronbach's alpha values are acceptable for all three constructs (see Table 2).

The composite reliability $(\mathrm{CR})$ values ranged from 0.807 to 0.909 , above the minimum level of 0.70 [12]. The values of the average variance extracted (AVE) ranged from 0.514 to 0.738 , all above the minimum level of 0.50 [12], thus confirming the convergent validity of the model.

The discriminant validity of constructs was examined through the squared correlations test [10]. The results in Table 2 show that with two exceptions, the square root of the AVE for each construct is greater than the correlations between constructs, which shows acceptable discriminant validity.

\begin{tabular}{|c|c|c|c|c|c|c|c|}
\hline & Alpha & $\mathrm{CR}$ & AVE & PEU & $\mathrm{PE}$ & $\mathrm{PU}$ & SAR \\
\hline PEU & 0.81 & 0.807 & 0.514 & 0.717 & & & \\
\hline PE & 0.93 & 0.930 & 0.816 & 0.574 & 0.903 & & \\
\hline PU & 0.78 & 0.788 & 0.555 & 0.738 & 0.699 & 0.745 & \\
\hline SAT & 0.91 & 0.909 & 0.769 & 0.577 & 0.895 & 0.727 & 0.877 \\
\hline
\end{tabular}

Notes: The bold diagonal numbers are the square root of AVE

\section{Structural model}

Structural equation modeling (SEM) was carried on to test the fit between the research model and the data. The structural model in Figure 1 shows the standardized path coefficients and the item loadings.
The model estimation results showed that PEU has a significant positive influence on $\mathrm{PE}(\beta=0.574, \mathrm{p}<0.001)$ and PU $(\beta=0.502, p<0.001)$ so the hypotheses $\mathrm{H} 1$ and $\mathrm{H} 2$ are supported. The influence of PEU on SAT is not significant so $\mathrm{H} 3$ is rejected. The path from $\mathrm{PE}$ to $\mathrm{PU}$ is also significant ( $\beta=0.410, p<0.001)$ so $H 4$ is supported. Both PE and PU have a significant effect on SAT $(\beta=0.70, p<0.001$, respectively $\beta=0.24, p=0.015$ ), providing support for hypotheses $\mathrm{H} 5$ and H6.

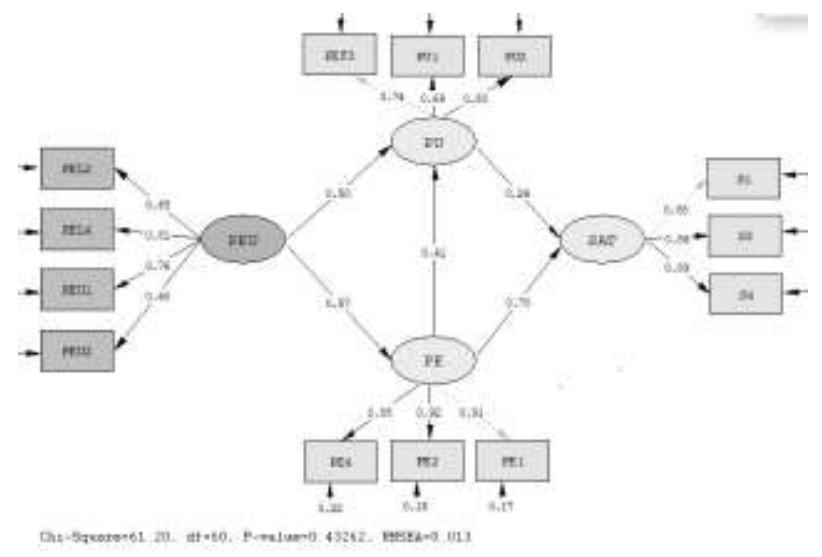

Figure 2. Structural model

The path coefficients show that the perceived enjoyment has a more important contribution than the perceived usefulness to the satisfaction with the platform. This is surprising since the e-learning platform is a pragmatic rather than a hedonic technology.

The model explains $33 \%$ of the variance in the perceived enjoyment, $65.7 \%$ in the perceived usefulness, and $77.9 \%$ in the satisfaction with the platform.

The structural model fits very well with the data. The $\chi^{2}$ test is nonsignificant $\left(\chi^{2}=61.20, d f=60, p=0.433\right)$. The other GOF indices are also indicating a very good fit: $\chi^{2} / d f=1.02$, $\mathrm{CFI}=0.999, \mathrm{GFI}=0.93, \mathrm{SRMR}=0.030, \mathrm{RMSEA}=0.013$.

\section{DISCUSSION}

This study contributes to a better understanding of relationships among those factors that influence students' perceptions concerning the usability of the Moodle platform as an efficient e-learning tool. The resulting model provides a good understanding of those variables, in order to improve teacher intervention.

From the psychological perspective, the Moodle platform's ease of use (PEU) represents a feature that does not force the student cognitive resources. In this sense, the used and learned algorithms gradually become automatisms and do not require an increased student's effort, contributing also to achieve a certain level of efficiency $(P U)$ in the activity carried out (quantified in results), but leading to a perceived enjoyment or level of attractiveness $(P E)$ related to the product. This perceived enjoyment mobilizes or energizes the learning activities, contributing to the increase in work efficiency. Practically, this is how the inner motivation for using such a platform appears.

Although the efficiency contributes to obtaining the satisfaction to a certain extent, the results show that perceived enjoyment $(\mathrm{PE})$ influences satisfaction (SAT) to 
a much greater extent. The measures of this construct are pointing to three attributes of the learning process: pleasant, attractive, and interesting. Perceived enjoyment has both a direct influence and an indirect influence mediated by the perceived usefulness.

The results are somehow surprising given the pragmatic nature of the platform and show that the attractiveness of a product can generate satisfaction to a greater extent than its efficiency, so how a product/content is presented must be taken into account.

The perceived ease of use has only an indirect influence on the satisfaction that is mediate buy the perceived enjoyment and perceived usefulness.

There are inherent limitations of this exploratory study. First, the sample is small (120 observations). Secondly, only three factors have been considered in this research. Future work should extend the scale by taking into account external variables, such as e-learning content.

\section{CONCLUSION}

The results obtained from the investigation concerning the usability of the Moodle platform illustrate that the respondents considered e-learning an interesting, pleasant, and efficient activity, which generates satisfaction and confidence in their ability to support learning. The strengths of the platform - ease of use, productivity, and facilitator of learning - have been highlighted by the students, most of them being convinced that they easily transfer their acquired skills in other distant learning situations if necessary. The results suggest that learning should be both attractive and interesting, but also find Moodle as a virtual environment proper to be exploited in the academic field, being very accessible to students.

\section{REFERENCES}

1. Aljawarneh, S. A. (2020). Reviewing and exploring innovative ubiquitous learning tools in higher education. Journal of Computing in Higher Education, 32, 57-73, DOI: 10.1007/s12528-019-09207-0.

2. Anarinejad, A., Mohammadi, M. (2020). The Practical Indicators for Evaluation of E-Learning in Higher Education in Iran. Interdisciplinary Journal of Virtual Learning in Medical Sciences, 5(1), 11-25.

3. Anderson, J.C., Gerbing, D.W. (1988). Structural Equation Modelling in Practice: A Review and Recommended Two-Step Approach. Psychological Bulletin 103 (3), 411-423.

4. Bremer, D., Bryant, R. (2005). A comparison of two learning management systems: Moodle vs Blackboard. Proceedings of $18^{\text {th }}$ Annual Conference of the National Advisory Committee on Computing Qualifications, Tauranga, New Zealand, 135-139.

5. Calli, L., Balcikanli, C., Calli, F., Cebeci, H. I., Seymen, O. F. (2013). Identifying factors that contribute to the satisfaction of students in e-learning. Turkish Online Journal of Distance Education, 14(1), 85-101.

6. Davis, F. D., Bagozzi, R. P., Warshaw, P. R. (1992). Extrinsic and intrinsic motivation to use computers in the workplace. Journal of Applied Social Psychology, 22(14), 1111-1132.
7. de Melo Pereira, F. A., Ramos, A. S. M., Gouvêa, M. A., $\&$ da Costa, M. F. (2015). Satisfaction and continuous use intention of e-learning service in Brazilian public organizations. Computers in Human Behavior, 46, 139148. DOI: $10.1016 /$ j.chb.2015.01.016.

8. Dolendo, M. E. (2016). Usability Measurement of Learning Management Systems: A Response to Educational Technology Influx. GSE E-Journal of Education, 4, 25-36. http://worldconferences.net/home 25.

9. Epping, R. J. (2010). Innovative Use of Blackboard [R] to Assess Laboratory Skills. Journal of Learning Design, 3(3), 32-36. https://www.learntechlib.org/p/ 55583.

10. Fornell, C., Larcker, D. F. (1981). Evaluating structural equation models with unobservable variables and measurement error. Journal of Marketing Research, 18(1), 39-50.

11. Gorghiu, G., Bîzoi, M., Gorghiu, L. M., Suduc, A. - M. (2009). Aspects Related to the Usefulness of a Distance Training Course Having Moodle as Course Management System Support. Proc. WSEAS International Conference on Distance Learning \& Web Engineering, Budapest, Hungary, 54-59.

12. Hair, J. F., Black, W. C., Babin, B. J., Anderson, R. (2006). Multivariate Data Analysis. 6th Ed., PrenticeHall

13. Meiselwitz, G., Sadera W. A. (2008). Investigating the Connection between Usability and Learning Outcomes in Online Learning Environments. MERLOT Journal of Online Learning and Teaching, 4(2), 234-242.

14. Mels, G. (2006). LISREL for Windows: Getting Started Guide. Lincolnwood: Scientific Software International Inc.

15. Nielsen, J. (1994). Heuristic Evaluation. In J. Nielsen \& R. L. Mack (Eds.). Usability Inspection Methods. New York, NY: John Wiley \& Sons

16. Oproiu, G. C. (2015). A Study about Using E-learning Platform (Moodle) in University Teaching Process. Procedia - Social and Behavioral Sciences, 180, 426432.

17. Pavlakou, E., Kalachanis, K. (2018). Adult Education Using the Moodle E-Learning Platform: The Role of the Trainer. Journal of Education \& Social Policy, 5(3), 105-109. DOI: 10.30845/jesp.v5n3p13.

18. Szirmai, M. (2020). Moodle: The Ubiquitous Teacher. Electronic Journal of Foreign Language Teaching, 17 (1), 190-204.

19. Usuf, B. N. (2020). Are we prepared enough? A case study of challenges in online learning in a private higher learning institution during the COVID-19 outbreaks. Advances in Social Sciences Research Journal, 7(5), 205-212. DOI: 10.14738/assrj.75.8211.

20. ***, Moodle statistics. https://moodle.net/stats 